
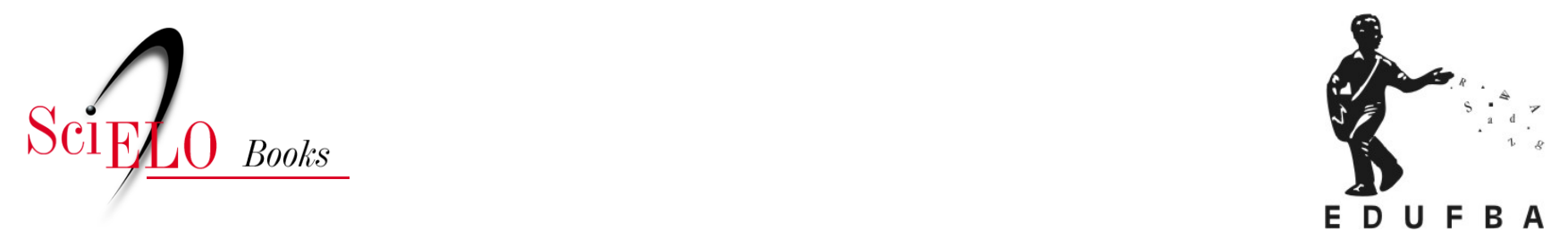

\title{
Situando o debate \\ Necessidades e problemas de saúde bucal no Brasil e tendências para as políticas de saúde
}

\author{
Maria Cristina Cangussu \\ Johelle Passos-Soares \\ Maria Beatriz Cabral
}

CANGUSSU, M.C., PASSOS-SOARES, J., and CABRAL, M.B. Necessidades e problemas de saúde bucal no Brasil e tendências para as políticas de saúde. In: CHAVES, S.C.L. Política de saúde bucal no Brasil: teoria e prática [online]. Salvador: EDUFBA, 2016, pp. 47-76. ISBN 978-85-232-2029-7.

https://doi.org/10.7476/9788523220297.0003.

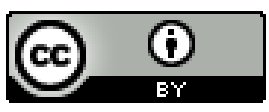

All the contents of this work, except where otherwise noted, is licensed under a Creative Commons Attribution 4.0 International license.

Todo o conteúdo deste trabalho, exceto quando houver ressalva, é publicado sob a licença Creative Commons Atribição 4.0. 


\section{Necessidades e problemas de saúde bucal no Brasil e tendências para as políticas de saúde}

Maria Cristina Cangussu

Johelle Passos-Soares

Maria Beatriz Cabral

\section{Introdução}

O presente capítulo propõe revisitar alguns problemas considerados importantes na saúde coletiva, bem como as ações desenvolvidas na atual Política Nacional de Saúde Bucal (PNSB) para o enfrentamento desses problemas na população. Na odontologia, utiliza-se como critérios de seleção e priorização dos problemas em saúde coletiva a magnitude, gravidade e vulnerabilidade do dano à saúde, bem como o impacto potencial das medidas de controle disponíveis para o seu enfrentamento. Outro aspecto muito importante é a transcendência social do problema e o grau de interferência na qualidade de vida dos indivíduos. (PINTO, 1994)

Nesse sentido, serão discutidos os aspectos epidemiológicos atuais dos seguintes problemas de saúde bucal: cárie dentária, doença periodontal, câncer bucal e fluorose, sendo também introduzidos outros problemas cuja relevância epidemiológica tem aumentado, seja em função das causas gerais de morbi-mortalidade, como os traumas dentários e de face, seja em função da mudança 
do perfil epidemiológico da população brasileira e importância social do problema, como as alterações de oclusão.

\section{Cárie dentária}

A cárie dentária é, ainda, um problema de saúde pública persistente na população brasileira. Estudos sistemáticos no país com o objetivo de mensurar a sua magnitude e severidade só ocorreram após 1950, no âmbito dos programas incrementais, seja para avaliar as estratégias adotadas à época pela Fundação Serviço de Saúde Pública, seja para justificar a intervenção em saúde bucal. (NARVAI, 2006)

Inquéritos de abrangência nacional que levaram em consideração amostras representativas, assim como estudos locais de cunho científico, tornaram-se mais frequentes a partir de 1980. (RONCALLI et al., 2012) Também nesse período, inúmeras iniciativas de organização dos serviços e mudanças na prática da saúde bucal, no contexto da Reforma Sanitária Brasileira puderam ser registradas. Na última década do século XX, e primeira do século XXI (já na vigência da atual PNSB), foram implantadas e expandidas importantes intervenções em saúde bucal em todo o país, tendo como referência o princípio constitucional da universalização das ações e serviços de saúde, a exemplo da fluoretação das águas de abastecimento público, do atendimento odontológico da rede pública do Sistema Único de Saúde (SUS) e da adição de compostos fluorados aos dentifrícios. (ANTUNES; NARVAI, 2010)

Destaca-se, nesse contexto, a partir de 2004, a PNSB, que também apresenta foco na saúde da família enquanto estratégia para a reorganização das práticas, ampliação e qualificação da atenção secundária e terciária através dos Centros de Especialidades Odontológicas (CEO) e Laboratórios Regionais de Prótese Dentária e a ampliação da fluoretação das águas de abastecimento público. (BRASIL, 2004a)

É importante assim, refletir sobre a realidade epidemiológica brasileira visando a reorientação de futuras ações da PNSB. Observa-se, de forma clara, uma tendência de redução da prevalência e severidade da cárie dentária na população jovem, consistente também com o controle da doença em grande parte do mundo ocidental, a exemplo do Brasil (Quadros 1 e 2), especialmente nos últimos 30 anos. Essa tendência também está presente em adultos jovens, embora com menor intensidade. Já aos cinco anos, continua apresentando condição persistente desse agravo, assim como adultos e idosos (Quadro 1). 
Quadro 1 - Média do CPOD/ceod nas idades/faixas etárias índices, segundo ano do levantamento epidemiológico nacional

\begin{tabular}{|l|c|c|c|c|}
\hline \multirow{2}{*}{ Idade - Faixas etárias } & \multicolumn{4}{|c|}{ CPOD/ceod } \\
\cline { 2 - 5 } & 1986 & 1996 & $2002-2003$ & 2010 \\
\hline 5 anos* $^{*}$ & - & - & 2,89 & 2,43 \\
\hline 12 anos & 6,65 & 3,06 & 2,78 & 2,07 \\
\hline $15-19$ anos & 12,68 & - & 6,17 & 4,25 \\
\hline $35-44$ anos & 22,50 & - & 20,13 & 16,75 \\
\hline $65-74$ anos $^{* *}$ & 27,22 & - & 27,79 & 27,03 \\
\hline
\end{tabular}

*valores referem-se ao ceod

**no ano de 1986, esse grupo correspondia a faixa etária de 50-59 anos.

Fonte: Brasil (1988), Brasil (1996), Brasil (2004a), Brasil (2011).

Destaca-se também em pré-escolares e jovens, um alto percentual de doença não tratada, bem como uma alta participação do componente perdido em adultos e idosos (Quadro 2), com redução maior apenas nas faixas etárias de 15-19 anos e 35-44 anos, entre os anos de 2002- 2003 e 2010.

Quadro 2 - Percentual de cárie não tratadas por faixas etária de 5, 12 e 15-19 anos e percentual de participação do componente perdido $(P)$ nas faixas etárias de 35-44 e 6574 anos, nos levantamentos nacionais após o ano 2000

\begin{tabular}{|l|c|c|c|c|}
\hline $\begin{array}{c}\text { Idade - Faixa } \\
\text { etária }\end{array}$ & \multicolumn{2}{|c|}{$\begin{array}{c}\text { Percentual de cárie não tratada no } \\
\text { CPOD (\%) }\end{array}$} & $\begin{array}{c}\text { Percentual de dentes perdidos no } \\
\text { CPOD (\%) }\end{array}$ \\
\hline & $2002-2003$ & 2010 & $2002-2003$ & 2010 \\
\hline 5 anos & 82,1 & 80,2 & 2,9 & 2,5 \\
\hline 12 anos & 58,3 & 54,1 & 6,5 & 5,8 \\
\hline $15-19$ anos & 42,1 & 35,8 & 14,4 & 8,9 \\
\hline 35-44 anos & 11,6 & 8,8 & 65,7 & 44,7 \\
\hline $65-74$ anos & 4,2 & 1,9 & 92,9 & 91,9 \\
\hline
\end{tabular}

Fonte: Brasil (2004a), Brasil (2011). 
Embora a redução da gravidade da doença, mensurada pela proporção de cárie não tratada e dentes perdidos mostre-se de extrema importância para o controle da doença em si, implementações de outras medidas necessárias aos serviços de saúde que deêm conta de uma das piores sequelas cumulativas da cárie, a perda do elemento dentário, requerem investimentos políticos e financeiros de modo assegurar a reabilitação protética de milhões de indivíduos.

Um dos grandes avanços da PNSB é explicitar a necessidade de reabilitação através da organização, implantação e expansão da cobertura dos CEO e Laboratórios Regionais de Prótese Dentária. (BRASIL, 2008) Tal fato pode ser confirmado pelo financiamento dessas ações, cujo montante de recursos envolveu, apenas no âmbito do governo federal, investimentos anuais que passaram de 56,5 milhões de reais, em 2003, para 427 milhões de reais, em 2005, e atingiram cerca de 600 milhões, em 2008, totalizando aproximadamente $\mathrm{R} \$ 2,4$ bilhões no período. (FRAZÃO; NARVAI, 2009)

O impacto dessas ações já pode ser percebido nas faixas etárias mais jovens (15 a 19 anos) e no maior uso de prótese na faixa etária de 65-74 anos (Quadro 3). Entretanto, a necessidade de saúde da população adulta permanece como uma demanda histórica, envolvendo alto grau de complexidade e de cobertura, a exemplo das próteses fixas e removíveis, que são menos ofertadas pelos serviços de saúde. (MIOTTO et al., 2012) Na população jovem, a redução do CPOD implica menor carga de doença e tem sido acompanhada da sua concentração em grupos específicos, reforçando as iniquidades em saúde e o fenômeno da polarização. (BRASIL, 2004a; NARVAI et al. 2006; BRASIL, 2011) Esse grupo, considerado de alto risco, necessitaria de ações específicas (ROSE, 2010), colocadas de forma complementar no guia de utilização de fluoretos no Brasil (BRASIL, 2009) incluindo a escovação dental supervisionada, bochechos fluorados, uso do flúor gel, vernizes e materiais com flúor, sendo, todos esses métodos, dependentes do acesso e cobertura dos serviços de saúde. É claro que existe a necessidade de adequação de cada um desses métodos ao perfil epidemiológico da população-alvo. 
Quadro 3 - Percentual do uso e necessidade de prótese nas faixas etárias de 15-19 anos, 35-44 e 65-74 anos, nos levantamentos nacionais após o ano 2000.

\begin{tabular}{|l|c|c|c|c|c|c|}
\hline \multirow{2}{*}{ Faixa etária } & \multicolumn{2}{|c|}{$\begin{array}{c}\text { Percentual uso de } \\
\text { prótese superior }\end{array}$} & \multicolumn{2}{c|}{$\begin{array}{c}\text { Percentual uso de } \\
\text { prótese inferior }\end{array}$} & \multicolumn{2}{c|}{$\begin{array}{c}\text { \% necessidade de } \\
\text { prótese }\end{array}$} \\
\hline & $\mathbf{2 0 0 2 - 2 0 0 3}$ & $\mathbf{2 0 1 0}$ & $\mathbf{2 0 0 2 - 2 0 0 3}$ & $\mathbf{2 0 1 0}$ & $\mathbf{2 0 0 2 - 2 0 0 3}$ & $\mathbf{2 0 1 0}$ \\
\hline 15-19 anos & 1,9 & 3,7 & 0,2 & 0,6 & 20,2 & 13,7 \\
\hline 35-44 anos & 48,3 & 32,8 & 15,3 & 10,1 & 70,1 & 68,8 \\
\hline 65-74 anos & 66,5 & 76,5 & 42,7 & 53,9 & 54,5 & 92,7 \\
\hline
\end{tabular}

Fonte: Brasil (2004a), Brasil (2011).

Ressalta-se, nos últimos 10 anos, a importância e diversidade da participação dos pesquisadores brasileiros nos estudos etiológicos sobre a cárie dentária. O Brasil possui mais de 9.000 artigos publicados no ISI Web of Science (Instituto para Informação Científica), nesse período, sobre a epidemiologia dessa alteração em todas as faixas etárias, sendo a maioria deles envolvendo crianças e adolescentes.

Estes apontam que, apesar dos inegáveis avanços no controle da cárie dentária, ainda persiste um quadro de iniquidade na distribuição da doença, identificado também nos levantamentos nacionais de 2002-2003 e 2010. A cárie está mais presente entre aqueles de menor nível socioeconômico ou maior vulnerabilidade social (BRASIL,1988; CARDOSO, 2003; CANGUSSU, CASTELLANOS, 2004; SOUZA et al., 2006), condições expressas, na maior parte dos trabalhos, por piores condições de vida, escolaridade ou renda. (ANTUNES; JAHN; CAMARGO, 2005; PEREIRA et al., 2010) Nos levantamentos nacionais, são visíveis as diferenças dos indicadores em relação ao porte populacional, acesso à água fluoretada e macrorregião do país. (BRASIL, 2004a; BRASIL, 2011)

Assim, não restam dúvidas que medidas sociais e econômicas mais gerais, voltadas ao enfrentamento da exclusão social e intervenções de saúde pública complementares de proteção à saúde bucal, dirigidas aos grupos mais vulneráveis, são fundamentais para o controle da doença.

Dentre as medidas de cobertura populacional que contribuíram para a redução da doença temos a fluoretação das águas de abastecimento público. $\mathrm{O}$ uso dessa tecnologia se iniciou há mais de meio século no país, com determinação legal - Lei ${ }^{0}$ 6.050, de 24 de maio de 1974, regulamentada pelo Decreto $\mathrm{n}^{\mathrm{o}} 76.872$, de 22 de dezembro de 1975. Em 2006, adotavam essa medida 45,7\% 
dos municípios brasileiros, beneficiando mais de 100 milhões de pessoas, aproximadamente $54 \%$ da população brasileira.

Contudo, os dados disponíveis apontam para uma extrema desigualdade no país com uma cobertura muito maior da fluoretação nos estados do Sul e Sudeste, onde se concentra a maior parte da riqueza, e insuficiente ou pouco sistematizada nas regiões Norte e Nordeste, onde, apenas as capitais e municípios com mais de 100.00 habitantes, com melhor renda e maior Índice de Desenvolvimento Humano a adotam. Assim, conforme coloca Antunes e Narvai (2010), uma das principais medidas de saúde pública efetiva na redução de desigualdades é, ela própria, objeto de profundas desigualdades em sua implantação.

A efetividade da fluoretação da água de abastecimento depende da sua manutenção e estabilidade dos teores de flúor dentro dos níveis adequados. Assim, o monitoramento constante dos equipamentos, bem como da manutenção da concentração de flúor dentro dos padrões recomendados é um problema nos sistemas de abastecimento. (RAMIRES; BUZALAF, 2007) A constatação de que, em muitas localidades brasileiras, ocorriam oscilações nas concentrações do flúor adicionado à água de abastecimento público, motivou a formulação de uma proposta para implantação de sistemas de vigilância sanitária da fluoretação das águas de abastecimento público, baseados no princípio do heterocontrole, embora ainda sejam escassos os estudos sobre o tema e o próprio monitoramento institucional no Brasil. (PANIZZI; PERES, 2008)

Afirma-se que a ação da fluoretação das águas no controle da cárie dentária diminui na atualidade, provavelmente, pelo emprego disseminado do flúor. É inegável que houve um aumento no uso de fontes alternativas de flúor, especialmente a adição do flúor aos dentifrícios, que, a partir de 1988, passaram a ser uma fonte significativa de flúor. A partir de 1990, praticamente 100\% dos dentifrícios vendidos no Brasil passaram a conter flúor em sua composição (LIMA; CURY, 2001), o que hoje contribui de forma significativa para a redução da experiência global de cárie no âmbito populacional. (NARVAI, 2006)

Do ponto de vista assistencial, outro elemento importante é que, de modo geral, o declínio da prevalência e severidade da cárie dentária não vem sendo acompanhado pela modificação dos padrões de oferta dos serviços de saúde. (NARVAI, 2006) Observa-se, no período entre 2004 e 2010, um expressivo crescimento na oferta de serviços de saúde na atenção básica, com quase o dobro de equipes de saúde bucal. Isso implicaria, por consequência, uma maior redução de dentes cariados e crescimento do componente restaurado, com 
maior impacto da reabilitação quando necessária. Entretanto, conforme pode ser constatado nos Quadros 2 e 3, a implantação da Estratégia Saúde da Família (ESF) e dos CEO, e o seu impacto ou resultado na saúde bucal da população brasileira, ainda é motivo de dissenso.

Narvai (2006) já colocava que a ampliação da cobertura dos serviços odontológicos, decorrente da descentralização do sistema de saúde brasileiro e dos investimentos no setor, assim como da maior disponibilidade de recursos odontológicos privados para a sociedade, não foi suficiente para alterar, significativamente, o padrão de composição do índice CPOD. Não há mudanças nos padrões de acesso e efetividade dos serviços, nem ao tipo de cuidado ofertado.

Reforçam esse argumento análises do modelo de atenção dos municípios com mais de 100.000 habitantes da região Nordeste, que encontraram resultados similares entre o modelo tradicional e a ESF nos aspectos relativos a morbidade, dor, acesso aos serviços, cobertura das ações curativas e preventivas. (PEREIRA et al., 2012) Assim, a incorporação da saúde bucal pelo setor público é ainda uma questão importante, considerando a magnitude do investimento e a proposta de inversão do modelo de atenção. Outros elementos precisarão ser analisados de forma local, como contexto político, organização e padrão da oferta dos serviços, processos de capacitação e envolvimento da equipe na prestação do cuidado, de forma a melhor compreender os seus papéis na organização à atenção à saúde bucal da população brasileira.

Por outro lado, as medidas populacionais têm, em muito, contribuído para a redução dos indicadores globais de cárie dentária no Brasil, mas de alguma forma, elas não superam completamente as iniquidades em saúde, visto que não são acessíveis a grupos de maior vulnerabilidade. Entretanto, apesar do aumento da oferta de serviços e a proposição de mudança do modelo assistencial, ainda é tímido o impacto sobre o perfil epidemiológico da população brasileira. A expansão histórica da rede, embora ainda insuficiente para atender às demandas existentes, assim como o investimento destinado às ações de saúde bucal e à implantação das equipes de saúde bucal na atenção básica e especializada, pouco tem contribuído para a melhoria dos indicadores epidemiológicos e assistenciais.

Assim, estratégias direcionadas a grupos com maior vulnerabilidade à doença, pautadas em planejamento local pelas equipes de saúde envolvidas, devem ser adotadas a fim de viabilizar a qualidade dessa cobertura ampliada 
dos serviços de saúde e a consequente melhoria do quadro de saúde bucal da população brasileira, especificamente, no que se refere à cárie dentária.

\section{Doença periodontal}

A prevalência da doença (presença de bolsas rasas e profundas) nos indivíduos entre 35 a 44 anos e naqueles com 65 e 74 anos de idade foi, respectivamente, de $19,4 \%$ e 3,3\% (BRASIL, 2011), sendo os sextantes posteriores os mais acometidos. A redução da periodontite no grupo de idosos é justificada pela grande proporção de sextantes excluídos (90,5\%), devido a grande perda dental, conforme o critério adotado (CPI), o que ratifica a precariedade da condição bucal da população brasileira com o avançar da idade, constituindo-se em um desafio atual para as autoridades sanitárias. Por outro lado, em uma leitura mais crítica, esse comportamento descritivo da doença nos idosos tem seu viés, uma vez que grande parte dos sextantes não foi examinada, mesmo apresentando uma unidade dentária presente, inclusive com a condição periodontal em diferentes níveis de gravidade. (NARVAI; GOMES-FILHO, 2011) A constatação da ausência da doença nas idades mais avançadas revela ainda que as estratégias adotadas para tratamento e controle da doença periodontal se concentram nas exodontias.

Figura 1 - Percentual de examinados segundo a condição periodontal, medida pelo Índice Periodontal Comunitário (CPI), e faixa etária (2003, 2010)

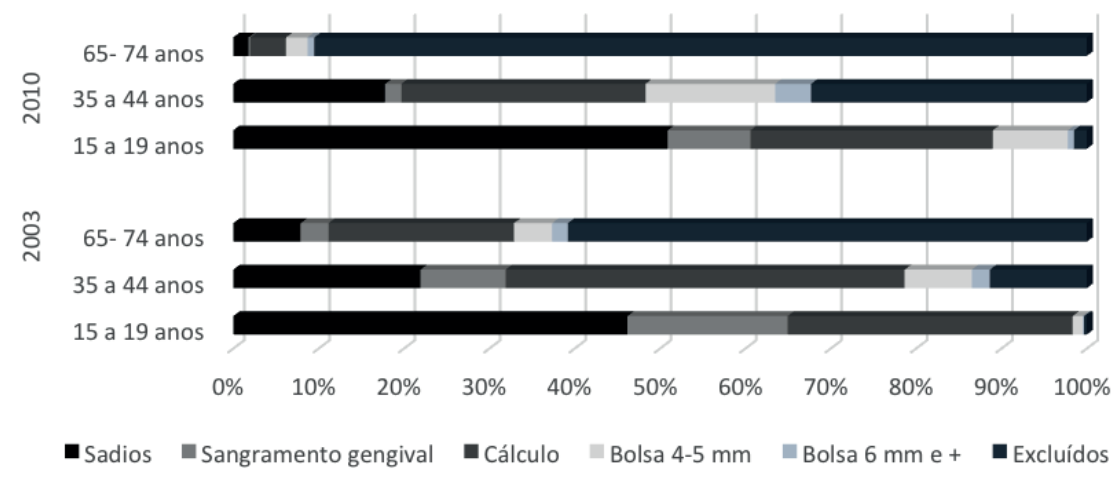

Fonte: Brasil (2004a, 2011). 
Nota-se que apesar da redução dos níveis de inflamação gengival na população entre os anos de 2003 e 2010, impulsionada pelas ações educativas para controle de biofilme, há necessidade de tratamento periodontal com acompanhamento contínuo para controle das medidas clínicas como profundidade de sondagem e nível de inserção clínica, as quais comprometem gravemente a estrutura de suporte do dente com o passar do tempo. A frequência de indivíduos com bolsas rasas (4-5 milímetros) e profundas (6 milímetros ou mais) têm aumentado, afetando, inclusive, as idades mais jovens.

Diversos fatores podem influenciar o desenvolvimento da doença periodontal como o hábito de fumar, gênero, algumas doenças sistêmicas como diabetes, uso de medicações, apinhamento dentário, nível socioeconômico, estresse e acesso aos serviços de saúde. (GENCO; BORGNAKKE, 2013; HAAS et al., 2014) Alguns estudos apontam também que esse agravo pode aumentar o risco de desenvolver condições sistêmicas como eventos cardiovasculares, doenças respiratórias, e nascimento de bebês de baixo peso. (SEYMOUR et al., 2007)

Explorar essas associações pode contribuir para melhor compreensão do processo saúde-doença periodontal e direcionar ações específicas no campo da saúde pública, de modo a intervir em fatores de risco comuns à doença e outros agravos sistêmicos. Porém, atuar sobre esses fatores, para alcance da qualidade de vida e nível ótimo de saúde, requer trabalho árduo, uma vez que não envolve somente a decisão do outro pela mudança de comportamento ou atitude frente à doença, mas uma abordagem interdisciplinar, integrada a diversos setores além da saúde, e pactuada com o indivíduo.

O forte gradiente social tem sido observado como determinante da doença periodontal. Estudos ecológicos mostram que indivíduos que vivem em áreas menos privilegiadas, com grande percentual de chefes de família sem instrução, apresentam piores condições gengivais. (PEREIRA et al., 2014) Esses espaços podem estar revelando que o nível de instrução e o poder aquisitivo vêm determinar as escolhas "impostas" por suas condições reais de vida, no que se refere, por exemplo, ao baixo consumo de produtos de higiene bucal nesse grupo. Dessa maneira, programas de saúde direcionados a essas áreas são essenciais para amenizar as iniquidades em saúde.

Diante desse cenário, do comportamento da doença periodontal nos grupos vulneráveis (gestantes, indivíduos com agravos sistêmicos, imunossuprimidos, e com precárias condições de vida), alguns desafios permanecem aos gestores da saúde. Apesar dos avanços com a expansão do número de equipes de saúde 
bucal no serviço público e oferta do serviço de periodontia no CEO, muitas dificuldades ainda são vivenciadas no controle da doença periodontal e tratamento das manifestações clínicas.

O incremento de periodontite na população, no período de 2003 a 2010, reforça o entendimento de que o aumento de 6 milhões de procedimentos especializados pelo SUS para 12,6 milhões, entre os anos de 2002-2012, e os R 48 milhões anuais destinados aos 1.037 CEO atuais, não têm sido suficientes para atender às necessidades periodontais da população. Em estudo que avaliou o desempenho dos CEO, no período de 2004 a 2009 (CORTELLAZZI et al., 2014), constatou-se que apenas 55,94\% dos CEO cumpriram as metas da periodontia, com percentuais inferiores para cirurgia $(33,07 \%)$ e endodontia $(22,61 \%)$. Isso nos leva a questionar sobre o efetivo papel do CEO no atendimento das necessidades acumuladas da população. Qual tem sido o seu desempenho frente em busca pelo serviço? Como tem sido utilizado os recursos investidos?

A realidade evidencia que, contrariamente ao proposto pela PNSB, a atenção básica não tem priorizado o encaminhamento ao serviço especializado dos casos complexos e com necessidade de terapia periodontal cirúrgica. Em alguns CEO, quase $100 \%$ dos procedimentos de periodontia estão relacionados à raspagem, alisamento e polimento sub e supragengival e raspagem coronoradicular, típicos da atenção primária. (CHAVES et al., 2011) Muitos desses encaminhamentos são determinados pela sobrecarga e falta de instrumentos e insumos adequados na atenção básica, bem como falta de clareza de suas atribuições no tratamento periodontal em relação aos demais níveis. A alta taxa de utilização dos serviços especializados de periodontia nos CEO, fruto principalmente desses encaminhamentos inadequados, tem resultado em longos tempos de espera para tratamento, em evasão e consequente impedimento de contrarreferência para atendimento na atenção básica.

Ainda no que se refere à organização dos serviços de saúde bucal, outra limitação observada refere-se à falta de integração e de planejamento interdisciplinar na atenção básica para assistência integral aos indivíduos suscetíveis a doença periodontal, como diabéticos e aqueles com outras doenças sistêmicas. As ações de saúde bucal têm se mantido fora do elenco das propostas do Ministério da Saúde voltadas ao controle da qualidade de vida de grupos de risco. (SILVA et al., 2010) No intuito de atender os princípios da integralidade, a equipe de saúde bucal necessita ser incluída nos grupos operativos de suporte e cuidado aos indivíduos com doenças crônicas, empregar na sua rotina as 
tecnologias para diagnóstico periodontal e compartilhar critérios pré-estabelecidos de tratamento e referenciamento. (SILVA et al., 2010)

Embora a literatura científica confirme o efeito de agravos sistêmicos na condição periodontal e vice-versa, é comum o encaminhamento desses indivíduos para consulta odontológica apenas em caso de "necessidade" ou determinada urgência. Um dos conflitos na interface entre atenção básica e especializada é percebido no modo de encaminhamento do paciente ao CEO, sem a realização devida de adequação do meio bucal e promoção de saúde bucal na atenção básica. (CHAVES et al., 2011) Com relação ao trabalho em equipe, observa-se a fraca incorporação do Técnico em Saúde Bucal na equipe odontológica, que tem como uma das atribuições a prática de higiene bucal supervisionada, orientação de higiene oral e remoção de cálculo dental. Apesar das resistências da categoria odontológica, essa inclusão aumentaria o escopo dos procedimentos e ampliaria o acesso às ações e serviços da rede.

Dessa forma, algumas ações estratégicas devem ser implementadas para minimizar os nós críticos na organização do serviço e diminuição das necessidades acumuladas. Dentre elas, destacam-se: a) busca ativa de indivíduos com problemas periodontais na comunidade, especialmente aqueles com sinais iniciais e que se enquadrem nos grupos de risco à doença; b) ajustes dos critérios predefinidos e do fluxo de referência e contrarreferência entre a atenção básica e especializada; e c) e manutenção periodontal pela atenção básica.

As ações estratégicas para prevenção e controle da doença periodontal (atividades de educação em saúde, remoção de fatores retentivos e raspagem supra e subgengival) devem ter como prioridade de atenção os grupos com idade mais jovem, no intuito de evitar a evolução para quadros mais graves. Para os indivíduos com alto risco de para desenvolverem a doença periodontal, as ações de planejamento em saúde devem envolver equipe multiprofissional e o estabelecimento de protocolo de atenção em saúde bucal, com definição dos procedimentos, inclusive aqueles a serem realizados exclusivamente nos CEO.

\section{Câncer bucal}

A mudança do perfil epidemiológico da população brasileira por conta do envelhecimento populacional e do padrão de consumo alimentar tem propiciado o crescimento das doenças crônicas, a exemplo, das neoplasias. O câncer bucal é uma das principais causas de morte por neoplasia que inclui cânceres com diversas localizações anatômicas e cujos valores de incidência têm aumen- 
tado no Brasil. Para o ano de 2014, o Instituto Nacional de Câncer José Alencar Gomes da Silva (INCA, 2014), estimou 11.280 casos novos de câncer bucal em homens e 4.010 em mulheres, sendo o quarto tipo de câncer mais frequente na região Sudeste (15,48/100 mil habitantes) e Nordeste (7,16/100 mil habitantes).

Dentre os variados tipos de câncer bucal, o carcinoma espinocelular ou epidermoide é o mais frequente ( $90 \%$ dos casos) e origina-se de lesões potencialmente malignas no epitélio de revestimento como leucoplasias, queilose actínica e eritroplasias. (SOUSA et al., 2014) Estudos nacionais têm identificado uma prevalência variando de $7 \%$ a $9 \%$ para as lesões potencialmente malignas (SOUSA et al., 2014), o que chama atenção para a identificação precoce dessas lesões e seu acompanhamento para prevenção do câncer bucal. Com relação às áreas anatômicas mais atingidas, o câncer de língua tem sido a categoria com mortalidade mais elevada. Os cânceres de lábio, área retromolar e gengiva têm sofrido queda nas taxas de mortalidade, ao contrário dos de orofaringe e áreas não especificadas da cavidade bucal. (SALOMÃO et al., 2013)

Quando se avalia o aumento na incidência de câncer bucal, acredita-se que a maior exposição aos fatores exógenos (ambientais e comportamentais) seja um fator influenciador do quadro, assim como o aumento dos exames diagnósticos, a busca ativa de casos suspeitos, e estímulo às notificações (SALOMÃO et al., 2013) com a política de saúde do governo.

Dentre os principais fatores de risco para o desenvolvimento de câncer bucal, destacam-se o tabagismo e o etilismo, sendo que a combinação desses dois hábitos tende a aumentar de forma multiplicativa a ocorrência da doença. (SOUSA et al., 2014) O incremento de mulheres fumantes têm favorecido a incidência nesse sexo. (LEITE et al., 2010) Outros fatores são apontados, como as infecções por HPV e a exposição à radiação UVA solar. Embora o câncer bucal acometa principalmente indivíduos com pelo menos 50 anos de idade, os jovens têm apresentado incidência de câncer bucal provocado pelo HPV, o que reforça a hipótese da influência da mudança de comportamento sexual na ocorrência dessas lesões.

O câncer bucal também apresenta uma forte relação com as iniquidades socioeconômicas, com maior incidência em indivíduos com piores condições de renda e instrução. (CONWAY et al., 2008) Essa distribuição desigual da doença na população reflete padrões diferenciais de acesso à informação e aos serviços de saúde. A dificuldade no acesso ao diagnóstico precoce e uso dos recursos 
terapêuticos, e o pior prognóstico do caso são mais evidentes nos indivíduos com maior privação social. (BIAZEVIC; ANTUNES, 2006)

Apesar da clareza sobre os potenciais fatores de risco à ocorrência da neoplasia bucal, a demora no diagnóstico, com identificação dos casos no último estágio, e a decisão clínica pelo tratamento mutilador como opção final, têm dado o tom das questões críticas a serem enfrentadas pela atual política de saúde bucal.

Estudos que têm avaliado a evolução das taxas de mortalidade por câncer na população evidenciam o aumento da mortalidade por câncer bucal ao longo dos anos, com maior frequência em homens do que em mulheres. (BOING et al., 2007, WÜNSCH FILHO; MONCAU, 2002; ) No período entre 1980 a 1995, as taxas de mortalidade exibiram um aumento de 2,9 a 3,3/100.000 homens e de 0,6 a, $8 / 100.000$ mulheres, influenciado pelos casos na faringe. Entre 2000 e 2004, constatou-se o contínuo incremento dessas taxas entre todas as regiões brasileiras, com o menor valor no Norte, fato provavelmente influenciado pelo baixo consumo de bebida alcoólica e tabagismo entre os indivíduos da região quando comparado às demais. (BOEING et al., 2006) Mesmo após a introdução da PNSB, que instituiu ações de recuperação (do diagnóstico ao tratamento) para controle da doença, esses números continuam a subir, alcançando a taxa ajustada de mortalidade de 4,54/100.000 homens e 0,97/100.000 mulheres no ano de 2013. (INCA, 2013)

A realização de exames periódicos em indivíduos de alto risco tem sido incentivada como estratégia populacional para redução dessa morbimortalidade. Entretanto, qual tem sido o impacto dessa medida no controle da doença? Pesquisas disponíveis sobre o impacto desses programas de rastreamento na redução das taxas de mortalidade são quase inexistentes. Em estudo nacional que avaliou os dados epidemiológicos da campanha "Abra a boca para a saúde", entre os anos de 2008 a 2013, concluiu-se que a população que procura a campanha não é o principal grupo de risco para a doença (NEOMOTO et al., 2015), o que leva a questionar sobre qual estratégia é mais eficaz para diagnóstico precoce da doença.

Sensibilizar os dentistas para a prevenção secundária do câncer bucal não é algo recente. Desde os anos 1930, essa preocupação era manifestada por meio de ações educativas junto aos profissionais dentistas. Entretanto, os primeiros sinais de envolvimento do governo com esse tópico se deram no ano de 1974, por meio da Divisão Nacional do Câncer (DNC) do Ministério da Saúde, ao 
promover, em vários estados, cursos de diagnóstico de câncer bucal. (SALTZ et al., 1998 apud TORRES-PEREIRA et al., 2012) Em 1976, a DNC, em parceria com a Sociedade Brasileira de Estomatologia, elaborou um documento com metas básicas para o Programa Nacional de Prevenção e Diagnóstico Precoce do Câncer da Boca (CABUL), propondo uma rede hierarquizada e permanente, ainda que vertical, e o treinamento de profissionais liberais até 1981. A realização de cursos de capacitação em câncer bucal foi realizada pelo Instituto Nacional de Assistência Médica da Previdência Social em vários estados nesse período, com criação de ambulatórios de controle da doença em Pernambuco e Bahia, posteriormente desativados. Nos anos 1980 e 1990, é criado o Programa de Expansão da Prevenção e Controle do Câncer da Boca, que vem enfatizar a importância da reabilitação pós-cirúrgica. Porém, até 2004, as ações de controle eram incipientes, sem difusão do conhecimento para coletividade ou adoção das medidas propostas.

Com o CEO na PNSB, cria-se um espaço para diagnóstico precoce de lesão bucal e acompanhamento dos casos junto às equipes de saúde bucal da atenção básica, a quem compete assumir responsabilidade pela detecção das necessidades, providenciar encaminhamentos e monitorar a evolução da reabilitação. (BRASIL, 2004) Porém, constata-se que algumas unidades de saúde não dispõem de referência regionalizada para encaminhamento necessário, dependendo de outras unidades para a realização de biópsia e de diagnóstico histopatológico, o que contribui para descontinuidade da atenção, agravando o quadro epidemiológico.

Para adequada ação diagnóstica, é dada ênfase no treinamento em estomatologia, por meio de cursos e acesso ao material instrucional, como condição essencial para ações de vigilância e prevenção secundária da doença. Apesar do reconhecimento do papel do dentista no diagnóstico precoce, alguns trabalhos revelam o despreparo dos profissionais na atenção básica para o diagnóstico de lesões bucais e realização de biópsias, criando mais uma barreira de acesso aos centros especializados para tratamento. (SOUSA et al., 2014) Outros autores ressaltam a necessidade de aproximar todas as categorias de profissionais de saúde envolvidas no conhecimento sobre câncer bucal, e de valorizar o trabalho multiprofissional com momentos de discussão, na medida em que muitas vezes os usuários tendem a procurar outros profissionais, que não o cirurgião-dentista, na ocorrência de uma lesão de boca. (LOMBARDO et al., 2014) 
Apesar dos esforços de mudança do modelo assistencial, a realidade atual do serviço demonstra ainda que os indivíduos com o câncer bucal ou lesão potencialmente maligna são acolhidos como demanda espontânea e em casos avançados. (TORRES-PEREIRA et al., 2012) Ampliar a possibilidade de detecção precoce com envolvimento dos agentes comunitários de saúde torna-se um caminho alternativo, com encaminhamento dos usuários de alto risco para exame clínico na unidade de saúde.

Quando se avalia o controle da doença nos serviços de média complexidade, constata-se que, do total de procedimentos de cirurgia oral menor, a realização de excisão e sutura de lesão de boca (passos primordiais para definição diagnóstica da lesão) tem variado entre $0,1 \%$ a $24,8 \%$, a depender do município. (CHAVES et al., 2011) Esse cenário conduz a uma reflexão sobre quais fatores podem estar interferindo nessa distribuição não equitativa de procedimentos especializados, e se a atenção básica tem conseguido desempenhar seu papel nas ações de encaminhamento e acompanhamento. Pesquisadores apontam ainda que a ausência de clareza sobre os padrões e metas propostas pelo serviço e mesmo a falta de pacientes podem ter reflexos na utilização dos procedimentos. (CHAVES et al., 2011)

Outro nó crítico em relação à rede de serviços, e que reflete nos números de mortalidade, é a dificuldade de acesso ao nível de alta complexidade (hospitais gerais de cirurgia oncológica e unidades e centros de alta complexidade oncológica). Segundo a Portaria n. ${ }^{\circ} 874 / 2013$, as unidades e centros de alta complexidade em oncologia que realizam o diagnóstico definitivo e o tratamento dos cânceres, têm como responsabilidade ofertar os serviços de cirurgia, radioterapia, quimioterapia, e cuidados paliativos. (BRASIL, 2013) Em 2010, a rede de atenção oncológica era composta por 276 hospitais aptos nos tratamentos dos diversos tipos de cânceres, sendo pelo menos um hospital em cada estado brasileiro habilitado para esse tratamento. No entanto, a articulação dos serviços de diagnóstico e de tratamento ainda é frágil e requer avanços importantes.

Ressalta-se a importância do diagnóstico dos principais problemas de lesão de boca mais prevalentes, uma vez que esse levantamento local norteará a elaboração de práticas integrais de saúde bucal específicas efetivas. Dessa forma, algumas estratégias gerais para controle da doença devem ser implementadas mais arduamente como: desenvolvimento de ações orientadas a indivíduos e grupos específicos, nos seus espaços cotidianos, como escolas e ambientes de trabalho, pelos profissionais de saúde; integração da equipe de saúde bucal aos 
programas de controle de tabagismo e etilismo; e estabelecimento e fortalecimento da rede de atenção oncológica, na qual a atenção básica possa se articular mais efetivamente com os serviços de média e alta complexidade.

\section{Fluorose dentária}

A fluorose dentária é um defeito de formação do esmalte, resultante da ingestão de flúor durante o desenvolvimento do dente, cujo comprometimento estético depende do efeito dose- resposta. A fluoretação das águas de abastecimento público consistia na única fonte de exposição sistêmica implantada enquanto ação pública coletiva de acesso ao flúor, antes dos anos 1970, no mundo, e, antes dos anos 1990, no Brasil. Na atualidade, o dentifrício fluoretado tem tido participação significativa na causalidade da fluorose (LIMA; CURY, 2001), principalmente em função da ingestão acidental em idades jovens.

Desde os primeiros registros sobre o efeito preventivo do flúor adicionado às águas de abastecimento, relatava-se uma prevalência esperada de 10\% a 15\% de fluorose muito leve. Na literatura nacional, revisões sistemáticas de trabalhos publicados, realizadas entre 1970 e 2006, identificaram grande diversidade de prevalências da alteração nas mais distintas regiões do país, variando de 1,7\% a 91,7\%, incluindo, entre eles, municípios com água fluoretada artificialmente, com proporções superiores ao valor esperado. (CANGUSSU et al., 2002; BARROS, TOMITA, 2010) Procurou-se atualizar essa sistematização com os artigos publicados nas bases de dados nacionais e internacionais, no período de 2005 a 2014. Incluíram-se os trabalhos sobre fluorose dentária que identificaram o município a que se referia a informação (com ou sem o ano de coleta de dados), o índice adotado, o tamanho da amostra e as idades contempladas, bem como a prevalência global da fluorose e dos casos moderados e severos (Quadro 4).

Apesar das grandes diferenças metodológicas e das prevalências obtidas da fluorose entre os estudos, é de fundamental importância ressaltar que os eles descrevem uma pequena proporção de casos moderados e severos (que provocam alterações estéticas e funcionais significativas), o que faz com que essa alteração não seja percebida como de relevância social para a comunidade e os pesquisadores não a identifiquem como um problema relevante de saúde pública. (PERES et al., 2007)

No Brasil, é recente a inclusão da fluorose dentária nos inquéritos nacionais. Sua ocorrência só foi investigada a partir do século XXI, tendo como resultado uma baixa prevalência e percentual insignificante das condições mais 
Quadro 4 - Estudos nacionais sobre a prevalência e severidade da fluorose dentária entre 2005 e 2014, segundo autor, ano de publicação, local, índice utilizado e presença de flúor na água de abastecimento público

(continua)

\begin{tabular}{|c|c|c|c|c|c|c|c|}
\hline Local (ano) & $\begin{array}{l}\text { Autor, ano de } \\
\text { publicação }\end{array}$ & Índice & $\mathrm{n}$ & $\begin{array}{l}\text { Idade } \\
\text { (anos) }\end{array}$ & $\begin{array}{c}\text { Prevalência } \\
\text { (\%) }\end{array}$ & $\begin{array}{c}\text { Casos moderados e } \\
\text { severos (\%) }\end{array}$ & Água fluoretada \\
\hline Catalão, GO (2001) & $\begin{array}{l}\text { Bardal et al., } \\
\quad 2005\end{array}$ & Dean & 432 & $7-12$ & 5,56 & - & $\operatorname{sim}$ \\
\hline Santa Tereza, RS (-) & $\begin{array}{l}\text { Toassi e Abegg, } \\
2005\end{array}$ & Dean & 259 & 4- 18 & 63,7 & 0,4 & $\operatorname{sim}$ \\
\hline Bauru, SP (-) & $\begin{array}{c}\text { Ramires et al., } \\
2006\end{array}$ & TF & 52 & $7-15$ & 33,0 & - & $\operatorname{sim}$ \\
\hline Salvador, BA (2004) & $\begin{array}{l}\text { Oliveira Jr. et al., } \\
2006\end{array}$ & Dean & $\begin{array}{l}521 \\
511\end{array}$ & $\begin{array}{l}12 \\
15\end{array}$ & $\begin{array}{l}32,6 \\
16,8\end{array}$ & $\begin{array}{l}0,76 \\
0,59\end{array}$ & sim \\
\hline $\begin{array}{l}\text { João Pessoa, PB (2004- } \\
\text { 2005) }\end{array}$ & $\begin{array}{c}\text { Carvalho et al., } \\
2007\end{array}$ & TF & 1114 & $12-15$ & 29,2 & 2,2 & $\operatorname{sim}$ \\
\hline $\begin{array}{l}\text { Povoados rurais do Norte, } \\
\text { MG (2006) }\end{array}$ & $\begin{array}{l}\text { Costa et al., } \\
2006\end{array}$ & TF & $\begin{array}{l}227 \\
153\end{array}$ & $\begin{array}{c}7-9 \\
10-12\end{array}$ & $\begin{array}{l}99,1 \\
90,0\end{array}$ & $\begin{array}{l}19,8 \\
34,6\end{array}$ & $\begin{array}{c}\text { Área de fluorose } \\
\text { endêmica }\end{array}$ \\
\hline Passo Fundo, RS (-) & Rigo et al., 2010 & Dean & 633 & $\begin{array}{c}12 \\
15-19\end{array}$ & $\begin{array}{l}36,2 \\
26,8\end{array}$ & 1,9 & $\operatorname{sim}$ \\
\hline
\end{tabular}


Quadro 4 - Estudos nacionais sobre a prevalência e severidade da fluorose dentária entre 2005 e 2014, segundo autor, ano de publicação, local, índice utilizado e presença de flúor na água de abastecimento público

(conclusão)

\begin{tabular}{|l|c|c|c|c|c|c|c|}
\hline $\begin{array}{l}\text { São Francisco do Conde, } \\
\text { BA (2010) }\end{array}$ & $\begin{array}{c}\text { Soares et al., } \\
2010\end{array}$ & Dean & 1474 & $7-13$ & 39,8 & 0,81 & $\operatorname{sim}$ \\
\hline São Paulo, SP (2008) & $\begin{array}{c}\text { Narvai et al., } \\
2013\end{array}$ & Dean & 4085 & 12 & 40,3 & 2,3 & $\operatorname{sim}$ \\
\hline São Paulo, SP (2010) & $\begin{array}{c}\text { Narvai et al., } \\
2013\end{array}$ & Dean & 231 & 12 & 38,1 & 1,7 & $\operatorname{sim}$ \\
\hline Manaus, AM (2008) & $\begin{array}{c}\text { Régis-Aranha et } \\
\text { al., 2014 }\end{array}$ & TF & 826 & 12 & 15,6 & - \\
\hline
\end{tabular}

Fonte: Lilacs e Scielo. 
severas. Assim sendo, aos 12 anos, observaram-se prevalências de 8,56\% e $16,70 \%$ (2002-2003 e 2010 respectivamente), e, dos 15-19 anos, prevalência de 5,14\% em 2002-2003. (BRASIL, 2004a; BRASIL, 2011)

Entretanto, como destaca Freitas e colaboradores (2013), existem muitos limites na interpretação desses dados nacionais, os quais compreendem: o tamanho insuficiente da amostra para avaliar a fluorose no âmbito municipal, o grande número de examinadores e, consequentemente, a confiabilidade dos dados. A prevalência da fluorose dentária apresentou uma variação considerável, de $\%$ a 61\%, em 2003, e de ०\% a 59\%, em 2010. Assim, foram observadas inconsistências nos dados em termos individuais (por ano e por capitais e regiões). No comportamento da tendência entre os anos de 2003 e 2010, observaram-se casos extremos, a exemplo do município de Salvador, que apresentou variações da prevalência que foram de 7,6\% (2003) a 44,3\% (2010), valores distintos do encontrado em estudos locais desenvolvidos nesse período. (OLIVEIRA et al., 2006)

Assim, consideram-se os dados nacionais apenas como exploratórios, devendo ser mais valorizados os resultados de estudos locais sobre o tema (FREITAS et al., 2006), com planos amostrais específicos e os cuidados metodológicos necessários para seu diagnóstico clínico e epidemiológico, levando-se em consideração a subjetividade na natureza da classificação. Ressalta-se que os estudos ainda são escassos (CANGUSSU et al., 2002; BARROS; TOMITA, 2010), dada a grande extensão geográfica e as distintas realidades do país.

Quando se analisa a produção brasileira nos últimos 10 anos em bases internacionais (ISIs; Web of Science), incluindo as palavras chave fluorose e epidemiologia, observa-se em média, 45 publicações ao ano. A maior parte dessa produção se refere à ocorrência e severidade da alteração em grupos específicos, à sua associação em relação a diferentes concentrações de flúor nas águas de abastecimento público ou à associação com a cárie dentária. Em menor quantidade, os estudos têm como objetivo associar a ocorrência da doença com outros fatores, como nível socioeconômico (RÉGIS-ARANHA et al., 2014) ou outras fontes de fluoreto. (CATANI et al., 2007)

A fluorose parece estar associada com níveis mais altos e contínuos do flúor na água de abastecimento público, mesmo nos casos de menor severidade. Como o uso dessa tecnologia é imprescindível para o controle da cárie dentária, faz-se necessária a expansão da fluoretação das águas no Brasil, ainda que tal medida represente algum impacto na fluorose dentária. Entretanto, a 
efetividade preventiva da fluoretação da água (maior benefício associado ao menor risco) depende da adequação do teor de flúor e da continuidade do processo. A interrupção, temporária ou definitiva, faz cessar o efeito da medida, e o teor elevado do flúor adicionado à água de abastecimento pode provocar danos maiores do que os já esperados. É indispensável o seu controle, seja em termos operacionais nas estações de tratamento de água, seja na vigilância sanitária. No primeiro caso, são importantes os procedimentos rotineiros de controle operacional. $\mathrm{Na}$ área de vigilância em saúde, é imprescindível o heterocontrole.

Já em relação à vigilância sanitária do flúor em dentifrícios, está comprovadamente associado à menor incidência de cárie dentária quando contém cerca de $0,1 \%$ (1.000 ppm) de flúor - geralmente na forma de monofluorfosfato de sódio. (CHAVES; VIEIRA-DA-SILVA, 2002) Na norma brasileira (Portaria SNVS n. ${ }^{\circ} 22$, de 20 de dezembro de 1989), recomenda-se que a concentração de flúor, na sua forma ativa, adicionada aos dentifrícios seja de pelo menos 600 ppm após 12 meses da data de fabricação e pelo menos 450 ppm "no restante do seu prazo de validade". A concentração mínima inicial é 1.000 ppm e o teor máximo permitido é de 1.500 ppm.

É comum a ingestão de dentifrício por crianças. Estima-se que menores de cinco anos ingerem cerca de $30 \%$ da quantidade utilizada em cada escovação, e tal ingestão, em quantidade excessiva de dentifrício fluorado, tem sido fortemente relacionada ao surgimento da fluorose dentária. (LIMA; CURY, 2001) A dose provavelmente tóxica do íon flúor é $5 \mathrm{mg}$ por $\mathrm{kg}$ de peso corporal. Para uma criança de $10 \mathrm{~kg}$, isso corresponde à ingestão em única dose de aproximadamente metade do conteúdo de um tubo com 90 gramas de pasta. Por essa razão, os pais ou responsáveis devem supervisionar as escovações dentárias até os seis anos de idade para reduzir a ingestão. O Código de Defesa do Consumidor já obriga também a informação dos modos de uso, quantidades e danos potenciais provocados pelo uso inadequado.

Os fabricantes deveriam orientar o uso da técnica transversal (o,35 grama/ escovação) para colocar o creme dental na escova (o longo eixo da escova posicionado perpendicularmente ao longo eixo do tubo). Ao contrário, a propaganda invariavelmente mostra o produto sendo dispensado segundo a técnica longitudinal (o,65 grama/escovação), e o maior consumo do produto irá, certamente, acarretar o maior risco de fluorose em crianças. 


\section{Problemas emergentes para enfrentamento pela PNSB}

Além dos problemas tratados anteriormente, considerados como prioritários para a concepção e desenvolvimento da PNSB, surgem outras condições de saúde bucal, seja por sua relevância epidemiológica, seja por sua relevância social. Entre elas, colocam-se, por exemplo, as alterações oclusais.

Muitos métodos e índices já foram propostos e desenvolvidos para avaliar as oclusopatias na população brasileira e no mundo. Os principais são o Index of Orthodontic Treatment Need, o Dental Aesthetic Index (DAI) e a apresentação dos desvios morfológicos ou de função mais comuns. Entretanto, poucos estudos foram desenvolvidos no Brasil.

Nos levantamentos nacionais, as oclusopatias foram avaliadas nas idades de 5 a 12 anos e na faixa etária de 15 a 19 anos, em 2002-2003 e 2010, respectivamente. Apesar de índices diferentes serem utilizados, aos cinco anos de idade, observaram-se altas prevalências da doença - 38,49\% (BRASIL, 2004a) e 66,7\% (BRASIL, 2011). Em adolescentes, o DAI foi o índice de eleição. No ano de 2004, os resultados foram mais graves do que no ano de 2010, sendo eles respectivamente: 12 anos - 21,59\% de maloclusão definida, 15,79\% maloclusão severa e $20,76 \%$ muito severa. Esses mesmos valores, em 2010 , corresponderam a $20 \%$, $11,2 \%$ e 6,5\% para a mesma idade. Já na faixa etária de 15 a 19 anos de idade, destaca-se, em 2004, a maloclusão definida com 20,44\%, maloclusão severa, $14,04 \%$, e a muito severa com $18,75 \%$. Em 2010 , os dados foram semelhantes para a maloclusão definida (20,3\%) e apontaram menor severidade, 6,2\% e 9,1\% respectivamente, para os casos de maloclusão severa e muito severa. (BRASIL, 2004a; BRASIL, 2011)

Os resultados de estudos locais se aproximam muito aos dos inquéritos nacionais na população escolar - 65,6\% em Juiz de Fora (ALMEIDA; LEITE, 2013), 40,1\% em Goiânia. (JORDÃO et al., 2015) Em Salvador, relatam-se dois estudos importantes, com percentual de 45,1\% (THOMAZ et al., 2013) e 33,61\%. (LOPES; CANGUSSU, 2005) De modo geral existe redução da severidade das alterações oclusais entre a dentição decídua e a permanente tanto em estudo realizado no estado de São Paulo como em estudos locais. (FRAZÃO et al., 2002)

Peres, Frazão e Roncalli (2013) assinalam que, no inquérito nacional de 2010, as oclusopatias mais graves estavam mais presentes em indivíduos pretos e pardos, com maior perda dentária e menor renda. Assim, a distribuição das oclusopatias em adolescentes brasileiros segue o padrão de iniquidade social de outros agravos à saúde e é necessário repensar os critérios relacionados, 
tanto com a distribuição e provisão de recursos quanto com as prioridades de tratamento, incluindo o ortodôntico, fundamentados no princípio da equidade da atenção à saúde bucal.

Soma-se a isso inúmeros relatos de intervenções equivocadas em populações jovens com o uso de aparelhos ortodônticos falsos, realizados com materiais de uso comum como clipes, elásticos, cerdas de vassoura, como também de materiais de uso profissional (fios e elásticos ortodônticos), destacando a relevância social da questão. Embora ainda não existam estudos sobre a magnitude do problema, bem como os relativos aos seus danos, do ponto de vista populacional (clinicamente, já são descritos casos de movimentação dentária inadequada, perda óssea e outras lesões periodontais), esse é um tema que precisa ser incorporado em uma pauta conjunta de atividades de educação em saúde e intervenção sobre as necessidades e riscos à saúde bucal. (GUZZO et al., 2014)

Ainda no tema dos problemas emergentes para a PNSB, destaca-se o traumatismo maxilofacial impulsionado pelo crescimento de fatores predisponentes como os acidentes de trânsito e a violência interpessoal (agressões físicas, uso de armas de fogo ou branca) embora, outras causas também tenham sido apontadas como os acidentes de trabalho, domésticos e relacionados ao esporte.

Apesar da magnitude que esse problema tem adquirido no contexto nacional, a maioria dos estudos publicados são resultantes de dados baseados em prontuários hospitalares e outros serviços de saúde, e não de base populacional. Os escassos estudos nacionais que investigaram o perfil epidemiológico do evento mostram que os ferimentos e fraturas dento-faciais causados por acidentes de trânsito variam entre $4 \%$ a $32 \%$ e os por violência, entre $11 \%$ e $43 \%$. (BATISTA et al., 2012; CAVALCANTI et al., 2009; CAVALCANTI et al., 2012; CAVALCANTI; MELO, 2009; SILVA et al., 2011; SANTOS et al., 2012) A variação na prevalência é determinada por fatores como as características da amostra do estudo (inclusão somente de crianças) e o perfil de violência da cidade (estudos como em João Pessoa, Paraíba, quarta cidade mais violenta do país). De modo geral, esses traumas são mais frequentes em homens, na faixa etária de 20 a 30 anos, nas áreas urbanas, durante a noite e nos fins de semana. Associações com ingestão de bebida alcoólica, uso de drogas e velocidade excessiva no trânsito têm sido ainda apontadas, e fatores contextuais como desemprego e má distribuição de renda podem ainda agravar esse panorama crítico. 
Quanto ao local de ocorrência desses traumas, os poucos estudos que analisaram esse aspecto, particularmente em crianças, revelam que os conflitos familiares representam mais um contexto influente na sua etiologia. A desestruturação familiar e a fragilidade das relações internas e externas estabelecidas parecem determinar a ocorrência dessas injúrias, apontadas como não intencionais (HARRIS; KOTCH, 1994), requerendo das pesquisas sobre etiologia dos traumas investigações perceptivas da existência de negligência e maus-tratos nos domicílios.

$\mathrm{Na}$ ocorrência desse agravo, independente da causa, o atendimento de urgência e de alta complexidade é necessário, o que, por sua vez, tem representado parte importante dos gastos públicos com vítimas de acidentes e violência. Em 2014, os acidentes de transporte e agressões corresponderam a $22 \%$ e 6\%, respectivamente, do valor dos serviços hospitalares voltados a causas externas. O tratamento do trauma maxilofacial geralmente é bastante complexo, com envolvimento de equipe multiprofissional e posterior acompanhamento, após o atendimento de urgência, sendo necessários procedimentos especializados, como endodontia, cirurgia e prótese, para resolução de fraturas radiculares, avulsões, perdas ósseas, luxações, intrusões, e outros, que requerem tempo e podem deixar sequelas. (SILVA et al., 2011) Essas sequelas envolvem também a dimensão psicológica do indivíduo, seja pelo comprometimento da estética ou restrições ao bem-estar físico, impactando sua vida no nível social e comportamental, ou pela experiência traumática do próprio evento.

Dessa forma, nesse cenário de discussão do trauma maxilofacial e suas repercussões, percebe-se que alguns elementos são requeridos para avanços na saúde pública como: a) sustentação de políticas de prevenção do trauma direcionadas às principais causas locais, incluindo aumento de supervisão policial em locais onde a violência é mais frequente, e melhorias da circulação de pedestres e veículos nas vias públicas; b) capacitação contínua dos profissionais envolvidos no atendimento ao traumatizado, não somente no manejo do caso, mas também na identificação da origem do trauma, especialmente em casos de violência domiciliar, para atuação mais efetiva dos setores relacionados; e c) incentivo à elaboração de protocolos-padrão para monitoramento de futuras sequelas após o trauma como necrose pulpar, anquilose da ATM (Articulação Temporomandibular) e má-oclusão, de modo a serem incorporados na rotina dos profissionais. 
Dada atual intensidade das causas externas (violência e acidentes) no cenário brasileiro e perfil do atendimento desses traumas nos serviços, cada vez mais os gestores precisam se planejar para alocar adequadamente profissionais e tecnologias necessárias para a assistência no nível da emergência/urgência dos casos, com ampliação de vagas hospitalares para profissionais da área de cirurgia e trauma bucomaxilofacial, bem como de oferta de serviço odontológico nas unidades de pronto atendimento. Além disso, deve se organizar o serviço, de modo a concretizar o acompanhamento efetivo desses traumatizados na rede pelo município, com garantia à atenção na unidade básica e especialidades como o CEO, e adequar a oferta dos serviços especializados (procedimentos endodônticos e reabilitação protética, por exemplo) conforme o perfil local, visando a redução e controle das sequelas.

\section{Considerações finais}

Houve importantes avanços na condição de saúde bucal brasileira nos últimos 20 anos. É incontestável a redução significativa da prevalência e da gravidade da cárie dentária em adolescentes e adultos jovens. Esse declínio, entretanto, não foi tão marcante na primeira infância e em idosos. O que fortemente parece ter contribuído para essa redução foram as medidas de controle no âmbito populacional, incluindo a fluoretação das águas de abastecimento público, a adição do flúor aos dentifrícios e o incremento das ações de promoção e proteção à saúde, implantadas com o intuito de diminuir as desigualdades sociais no Brasil nesse período. Ainda há fragilidade no enfrentamento de outros problemas como a doença periodontal, câncer bucal, assim como novos problemas epidemiológicos emergentes. Destaca-se que a PNSB estimulou a expansão de medidas populacionais, embora ainda tenha grandes dificuldades em reduzir as iniquidades em saúde, compreendidas como desigualdades injustas e evitáveis, visto que muitas das ações de saúde são inacessíveis às populações mais vulneráveis.

Uma questão que também precisa ser enfrentada é a relação entre o crescimento do investimento, a oferta de serviços e o impacto e resultados produzidos na adequação às necessidades de saúde bucal da população brasileira, independente dos problemas de saúde considerados prioritários. Aqui, colocase não só a qualidade da oferta, mas também a sua efetividade e adequação à condição epidemiológica no nível local. É preciso fortalecer a descentralização da saúde e a avaliação dos sistemas locais para melhoria dos serviços. 


\section{Referências}

ALMEIDA, A. B.; LEITE, I. C. G. Orthodontic treatment need for Brazilian schoolchildren: a study using the Dental Aesthetic Index. Dental Press Journal of Orthodontics, Maringá, v. 18 , n. 1, p. 103-109, 2013.

AMERICAN ACADEMY OF PERIODONTOLOGY (AAP). Position paper: tobacco use and the periodontal patient. Research, science and therapy committee of the American Academy of Periodontology. Journal of periodontology, Chicago, v. 70, p. 1419-1427, 1999.

ANTUNES, J. L.; JAHN, G. M.; CAMARGO, M. A. Increasing inequalities in the distribution of dental caries in the Brazilian contexto in Finland. Community Dental Health, Sheffield, v. 22, n. 2, p. 94-100, 2005.

ANTUNES, J. L. F.; NARVAI, P. C. Políticas de saúde bucal no Brasil e seu impacto sobre as desigualdades em saúde. Revista de Saúde Pública, São Paulo, v. 44, n. 2, p. 360-365, 2010.

BARDAL, P. A. P.; et al. Dental caries and dental fluorosis in 7-12-year-old schoolchildren in Catalão, Goiás, Brazil. Journal of Applied Oral Science, Bauru, v. 13, n. 1, p. 35-40, 2005.

BARROS, B. S. de A.; TOMITA, N. E. Aspectos epidemiológicos da fluorose dentária no Brasil: pesquisas no período 1993-2006. Ciências \& Saúde Coletiva, Rio de Janeiro, v. 15, n. 1, p. 289-300, 2010.

BATISTA, A. M. et al. Urban-rural differences in oral and maxillofacial trauma. Brazilian Oral Research, São Paulo, v. 26, n. 2, p. 132-138, 2012.

BIAZEVIC, M. G. H.; ANTUNES, J. L. F. Câncer Bucal. In: ANTUNES, J. L. F; PERES, M. A. A. (Org.). Epidemiologia da Saúde Bucal. Rio de Janeiro: Guanabara-Koogan, 2006.

BOING, A. F.; VARGAS, S. A. L.; BOING, A. C. A carga das neoplasias no brasil: mortalidade e morbidade hospitalar entre 2002-2004. Revista da Associação Médica Brasileira, São Paulo, v. 53, n. 4, p. 317-222, 2007.

BOMFIM, M. de L. et al. Social determinants of health and periodontal disease in Brazilian adults: a cross-sectional study. BMC Oral Health, Londres, v. 20, p. 13- 22, 2013.

BRASIL. Ministério da Saúde. Cadernos de Atenção Básica. Brasília, DF, 2008. n. 17.

BRASIL. Ministério da Saúde, Secretaria de Atenção à Saúde, Departamento de Atenção Básica, Coordenação Nacional de Saúde Bucal. Condições de Saúde Bucal da População Brasileira 2002-2003. Resultados Principais. Brasília,DF, 2004a.

BRASIL. Ministério da Saúde. Diretrizes da política nacional de saúde bucal. Brasília, DF, , 2004b.

BRASIL. Ministério da Saúde, Secretaria de Atenção à Saúde, Departamento de Atenção Básica. Guia de recomendações para o uso de fluoretos no Brasil. Brasília, DF, 2009.

BRASIL. Ministério da Saúde, Secretaria de Políticas de Saúde, Área Técnica de Saúde Bucal. Levantamento epidemiológico de cárie dentária, 1996. DATASUS. Disponível em: < http://tabnet.datasus.gov.br/cgi/sbucal/sbdescr.htm>. Acesso em: 1 nov. 2012. 
BRASIL. Ministério da Saúde, Secretaria Nacional de Programas Especiais de Saúde, Divisão Nacional de Saúde Bucal. Levantamento epidemiológico em saúde bucal: Brasil, zona urbana, 1986. Brasília, DF, 1988.

BRASIL. Ministério da Saúde, Secretaria de Atenção à Saúde, Departamento de Atenção Básica, Coordenação Nacional de Saúde Bucal. SB Brasil 2010. Pesquisa Nacional de Saúde Bucal. Resultados Principais. Brasília, DF, 2011.

BRASIL. Ministério da Saúde. Portaria no 874, de 16 de maio de 2013. Disponível em: http:// bvsms.saude.gov.br/bvs/saudelegis/gm/2013/prto874_16_05_2013.html. Acesso em: 25 ago. 2015 .

CANGUSSU, M. C. T. et al. A fluorose dentária no Brasil: uma revisão crítica. Cadernos de Saúde Pública, Rio de Janeiro, v. 18, n. 1, p. 7-15, 2002.

CANGUSSU, M. C. T.; CASTELLANOS, R. A. F. Prevalência de cárie dentária em escolares de 12 e 15 anos de Salvador, Bahia, 2001. Revista Brasileira de Saúde Materno Infantil, Recife, v. 4 , n. 3, p. 287-97, 2004.

CARDOSO, A.C.C. A associação entre cárie e fluorose dentária com a fluoretação das águas em dois municípios do estado da Bahia. Revista Baiana de Saúde Pública, Salvador, v. 27, n. $1 / 2$, p. $7-18,2003$.

CARVALHO, R. W. F. et al. Estudo da prevalência de fluorose dentária em Aracaju. Ciência \& Saúde Coletiva, Rio de Janeiro, v. 15, p. 1875-80, 2010.

CARVALHO, T. S.; KEHRLE, H. M.; SAMPAIO, F. C. Prevalenceandseverityof dental fluorosisamongstudentsfrom João Pessoa, PB, Brazil. Brazilian Oral Research, São Paulo, V. 21, p. 198-203, 2007.

CATANI, D. B. et al. Relação entre níveis de fluoreto na água de abastecimento público e fluorose dental. Revista de Saúde Pública, São Paulo, v. 41, p. 732-9, 2007.

CAVALCANTI, A. L; LIMA, I. J. D DE; LEITE, R. B. Perfil dos pacientes com fraturas maxilo-faciais atendidos em um hospital de emergência e trauma, João Pessoa, PB, Brasil. Pesquisa Brasileira de Odontopediatria, João Pessoa, v. 9, n. 3, p. 339-345, 2009.

CAVALCANTI, A .L et al. Traumatismos maxilofaciais em crianças e adolescentes em Campina Grande, Paraíba, Brasil. Pesquisa Brasileira de Odontopediatria, João Pessoa, v. 12, n. 3, p. 439-445, 2012.

CAVALCANTI, A. L; MELO, T. R. N. B. Lesões faciais em pacientes pediátricos de 1 a 4 anos de idade: um estudo retrospectivo. RPG Revista de pós-graduação, v. 16, n. 1, p. 19-25, 2009.

CHAMBRONE, L. et al. Prevalência e severidade de gengivite em escolares de 7 a 14 anos: condições locais associadas ao sangramento à sondagem. Ciência \& Saúde Coletiva, Rio de Janeiro, v. 15, n. 2, p. 337-343, 2010.

CHAVES, S. C. L. et al. Avaliação da oferta e utilização de especialidades odontológicas em serviços públicos de atenção secundária na Bahia, Brasil. Caderno de Saúde Pública, Rio de Janeiro, v. 27, n. 1, p. 143-154, 2011. 
CHAVES, S. C. L.; VIEIRA-DA-SILVA, L. M. A efetividade do dentifrício fluoretado no controle da cárie dental: uma meta-análise. Revista de Saúde Pública, São Paulo, v. 36, n. 5, p. 598-606, 2002.

CHAVES, S.C. L. et al. Avaliação da oferta e utilização de especialidades odontológicas em serviços públicos de atenção secundária na Bahia, Brasil. Cadernos de Saúde Pública, Rio de Janeiro, v. 27, n. 1, p. 143-154, 2011.

CHIAPINOTTO, F. A. et al. Risk factors for gingivitis in a group of Brazilian schoolchildren. Journal of Public Health Dentistry, Malden, v. 73, n. 1, p. 9-17, 2013.

CONWAY, D.I. et al. Socioeconomic inequalities and oral cancer risk: a systematic review and meta-analysis of case-control studies. International Journal of Cancer, New York, v. 122, p. 2811-2819, 2008.

CORTELLAZZI, K. L. et al. Variáveis associadas ao desempenho de Centros de Especialidades Odontológicas no Brasil. Revista Brasileira de Epidemiologia, São Paulo,v.17, n.4, p. 978-988, 2014.

COSTA, S. M.; et al. Cárie dentária e fluorose endêmica em distritos rurais de Minas Gerais, Brasil. Revista Brasileira de Epidemiologia, São Paulo, v. 16, n. 4, p. 1021-1028, 2013.

EKE, P. I.; et al. Update on Prevalence of Periodontitis in Adults in the United States: NHANES 2009 to 2012. Journal of Periodontology, Chicago, v. 86, n. 5, p. 611-622, 2015.

FRAZAO, P. et al . Prevalência de oclusopatia na dentição decídua e permanente de crianças na cidade de São Paulo, Brasil, 1996. Caderno de Saúde Pública, Rio de Janeiro, v. 18, n. 5, p. 1197-1205, out. 2002.

FRAZÃO, P.; NARVAI, P. C. Saúde bucal no Sistema Único de Saúde: 20 anos de lutas por uma política pública. Saúde Debate, São Paulo, v. 33, n. 8, p. 164-71, 2009.

FREITAS, C. H. S. M. et al. Reflexões metodológicas sobre prevalência da fluorose dentária nos inquéritos de saúde bucal. Revista de Saúde Pública, São Paulo, v.47, Suppl 3, p. 138-147, 2013.

GENCO, R. J.; BORGNAKKE, W. S. Riskfactors for periodontal disease. Periodontology 2000, Copenhagen, v. 62, n. 1, p. 59-94, 2013.

GUZZO, S. C. et al. Ortodontia preventiva e interceptativa na rede de atenção básica do SUS: perspectiva dos cirurgiões-dentistas da Prefeitura Municipal de Florianópolis, Brasil. Ciência \& Saúde Coletiva, Rio de Janeiro, v. 19, n. 2, p. 449-460, 2014.

HAAS, A. N. et al. Risk factors for the progression of periodontal attachment loss: a 5-year population-based study in South Brazil. Journal of Clinical Periodontology, Copenhagan, v. 41, n. 3, p. 215-23, 2014.

HARRIS, M. J.; KOTCH, J. B.Unintentional infant injuries: sociodemographic and psychosocial factors. Public Health Nursing, Malden, v. 11, n. 2, p. 90-97, 1994.

INCA. Instituto Nacional de Câncer José Alencar Gomes da Silva. Coordenação de Prevenção e Vigilância. Estimativa 2014: incidência de câncer no Brasil. Rio de Janeiro: 
INCA, 2014. Disponível em: <http://www.inca.gov.br/estimativa/2014/estimativa-24042014. pdf>. Acesso em 28 set. 2015.

INCA. Instituto Nacional de Câncer. Atlas online de mortalidade. 2014. Disponível em: <https://mortalidade.inca.gov.br/MortalidadeWeb/pages/Modeloo3/consultar. xhtml\#panelResultado>. Acesso em: 28 set. 2015 .

JORDÃO, L. M. R. et al. Individual and contextual determinants of malocclusion in 12-year-old schoolchildren in a Brazilian city. Brazilian Oral Research, São Paulo, v. 29, n.1, p.1-8, 2015 .

LEITE, I.C.G. Mortalidade por Câncer de Boca e Faringe em Cidade de Médio Porte na Região Sudeste do Brasil, 1980-2005. Revista Brasileira de Cancerologia. Rio de Janeiro, v. 56, n. 1, p. 17-23, 2010.

LIMA, Y. B. DE O.; CURY, J. A. Ingestão de flúor por crianças pela água e dentifrício. Revista de Saúde Pública, São Paulo, v. 35, n. 6, p. 576-581, 2001.

LOMBARDO, E. M. et al. Atrasos nos encaminhamentos de pacientes com câncer bucal: avaliação qualitativa da percepção dos cirurgiões-dentistas. Ciência \& Saúde Coletiva, Rio de Janeiro, v. 19, n. 4, p. 1233-1232, 2014.

LOPES, L. S.; CANGUSSU, M. C. T. Prevalência e severidade das alterações oclusais em escolares de 12 a 15 anos de Salvador - Bahia, Brasil, 2004. Revista de Ciências Médicas e Biológicas, Salvador, v. 4, n. 2, p. 105-112, 2005.

MENEGHIM, M. DE C. et al. Classificação socioeconômica e sua discussão em relação à prevalência de cárie e fluorose dentária. Ciência \& Saúde Coletiva. Rio de Janeiro, v.12, n. 2, p. 523-529, 2007

MiOTTO, M. H. M. DE B.; BARCELLOS, L. A.; VELTEN, D. B. Avaliação do impacto na qualidade de vida causado por problemas bucais na população adulta e idosa em município da Região Sudeste. Ciência \& Saúde Coletiva, Rio de Janeiro, v. 17, n. 2 p. 397-405, 2012

NARVAI, P. C. Saúde bucal coletiva: caminhos da odontologia sanitária à bucalidade. Revista de Saúde Pública, São Paulo, v. 40, p.141-147, 2006.

NARVAI, P. C. et al. Cárie dentária no Brasil: declínio, iniqüidade e exclusão social. Revista Panamericana de Salud Pública, Washington, v. 19, n. 6, p. 385-393, 2006.

NARVAI, P. C.; GOMES-FILHO, I. S. Epidemiologia em saúde bucal. Em: Naomar de Almeida Filho; Maurício Lima Barreto. (Org.). Epidemiologia saúde: fundamentos, métodos, aplicações. Rio de Janeiro: Guanabara-Koogan. 2011.

NARVAI, P. C. et al. Fluorose dentária em crianças de São Paulo, SP, 1998-2010. Revista de Saúde Pública, São Paulo, v. 47, n. 3, p. 148-53, 2013.

NEMOTO, R. P. et al. Oral cancer preventive campaigns: are we reaching the real target? Brazilian Journal Otorhinolaryngol, São Paulo, v. 81, n. 1, p. 44-49, 2015. 
OLIVEIRA, A. G. R. C. Levantamentos epidemiológicos em saúde bucal no Brasil. In: ANTUNES, J.L.F.; PERES, M.A. (Org.). Fundamentos de odontologia. Epidemiologia da saúde bucal. Rio de Janeiro: Guanabara Koogan, 2006.

OLIVEIRA, J. S. R. de et al. Fluorose dentária em escolares de 12 e 15 anos de idade. Salvador, Bahia, Brasil, nos anos 2001 e 2004. Cadernos de Saúde Pública, Rio de Janeiro, v. 22, n.6, p. 1201-1206, 2006.

PANIZZI, M.;PERES, M. A. Dez anos de heterocontrole da fluoretação de águas em Chapecó, Estado de Santa Catarina, Brasil. Cadernos de Saúde Pública, São Paulo, v. 24, n. 9, p. 2021-2031, 2008.

PEREIRA S. M. et al. Geographicinformation system (GIS) in assessing dental health. International Journal of Environmental Research and Public Health, Basel, Suiça, v. 7, n. 5, p. 2423-2436, 2010.

PEREIRA, C. R. S. et al. Impacto da Estratégia de Saúde da Família sobre indicadores de saúde bucal: análise em municípios do Nordeste brasileiro com mais de 100 mil habitantes. Cadernos de Saúde Pública. São Paulo, v. 28, n. 3, p. 449-462, 2012.

PEREIRA, S. M. et al. Geographic information system and multilevel analysis: gingival status in 12-year-old schoolchildren. Revista Panamericana de Salud Pública, Washington, DC, v. 35, n. 2, p. 136-143, 2014.

PERES, K. G.; FRAZÃO, P.; RONCALLI, A. G. Padrão epidemiológico das oclusopatias muito graves em adolescentes brasileiros. Revista de Saúde Pública, São Paulo, v. 47, n. 3 , p. 109-117, 2013.

PETERSEN, P.E. The world oral health report 2003: continuous improvement of oral health in the 21st century-the approach of the who global oral health programme. Community Dentistry and Oral Epidemiology, v. 31, n.1, p. 3-23, 2003.

PINTO, V. G. Saúde bucal, odontologia preventiva e social. 4. ed. São Paulo: Editora Santos, 1994.

PINTO, R. DA S.; MATOS, D. L.; LOYOLA FILHO, A. I. DE. Características associadas ao uso de serviços odontológicos públicos pela população adulta brasileira. Ciência \& Saúde Coletiva, Rio de Janeiro, v. 17, n. 2 , p. 531-544, 2012.

RAMIRES, I.; BUZALAF, M. A. A fluoretação da água deabastecimento público e seus benefícios no controleda cárie dentária - cinquenta anos no Brasil. Ciência \& Saúde Coletiva, Rio de Janeiro, v. 12, n. 4, p. 1057-1065, 2007.

RÉGIS-ARANHA, L. DE A et al. L. Relation between oral health and socioeconomic variables among schoolchildren aged 12 in the City of Manaus - AM. Acta Amazonica, Manaus, v. 44, n. 3, p. 321-32, 2014.

RIGO, L. et al. Estudo sobre a fluorose dentária num município do Sul do Brasil. Ciência \& Saúde Coletiva, Rio de Janeiro, v. 15, p. 1439-48, 2010.

RONCALLI, A.G. et al. Aspectos metodológicos do Projeto SB Brasil 2010 de interesse para inquéritos nacionais de saúde. Cadernos de Saúde Pública, Rio de Janeiro, v. 28, p. 40-57, 2012. 
ROSE, G. Estratégias da medicina preventiva. Porto Alegre: Artmed; 2010.

SALOMÃO, F. G. D.; DIAS, A. A.; PEREIRA, A. C. Prevenção do câncer em saúde bucal. In: PEREIRA, A. C. Saúde Coletiva: métodos preventivos para doenças bucais. Porto Alegre: Artes médicas. 2013. (Série Abeno).

SANTOS, C. M. L.et al. Estudo epidemiológico dos traumas bucomaxilofaciais em um hospital público de Feira de Santana, Bahia de 2008 a 2009. Revista Bahiana de Saúde Pública, Salvador, v. 36, n. 2, p. 502-513, 2012.

SEYMOUR, G.J.; et al. Relationship between periodontal infections and systemic disease. Clinical Microbiology and Infection, Paris, v. 13, n. 4, p. 3-10, 2007.

SILVA, A. M. et al .A integralidade da atenção em diabéticos com doença periodontal. Ciência \& Saúde Coletiva, Rio de Janeiro, v. 15, n. 4, p. 2197-2206, 2010.

SILVA, H. R. DA et al. Perfil epidemiológico do trauma dentário e facial em Curitiba. Archives of Oral Sciences \& Research, Bangalore, India, v. 7, n. 3, p. 267-273, 2011.

SOARES, F. F. et al. Prevalência e severidade de fluorose em escolares do município de São Francisco do Conde-BA, 2010. Revista de Odontologia da UNESP, Marília, v. 41, n. 5, p. 318-323, 2012.

SOUSA, F. B. et al . Oral cancer from a health promotion perspective: experience of a diagnosis network in Ceará. Brazilian Oral Research, São Paulo, v. 28, p. 1-8, 2014 .

SOUZA, M. A. A; VIANNA, M. I. P.; CANGUSSU, M. C. T. Disfunção familiar referida pela presença de depressão materna e/ou alcoolismo na família e ocorrência de cárie dentária em crianças de dois e três anos de idade. Revista Brasileira de Saúde Materno Infantil, Recife, v. 6, n. 3, p. 309-17, 2006.

THOMAZ, E. B. A. F.; CANGUSSU, M. C. T; ASSIS, A. M. A. Malocclusion and deleterious oral habits among adolescents in a developing area in northeastern Brazil. Brazilian Oral Research, São Paulo, v. 27, n.1, p. 62-69; 2013.

TOASSI, R. F. C.; ABEGG, C. Fluorose dentária em escolares de um município da serra gaúcha, Rio Grande do Sul, Brasil. Cadernos de Saúde Pública, Rio de Janeiro, v. 21, n. 2, p. $625-655,2005$.

TORRES-PEREIRA, C. C. et al . Abordagem do câncer da boca: uma estratégia para os níveis primário e secundário de atenção em saúde. Cadernos de Saúde Pública, Rio de Janeiro, v. 28, p. s3o-s39, 2012.

WHO. The World Oral Health Report 2003. Continuous improvement of oral health in the 21st century - the approach of the WHO Global Oral Health Programme. Geneva: WHO, 2003 .

WÜNSCH FILHO, V.; MONCAU, J. E. Mortalidade por câncer no brasil 1980-1995: padrões regionais e tendências temporais. Revista da Associação Medica Brasileira, São Paulo, v. 48, n. 3, p. 250-257, 2008. 